\title{
Effects of Ozonated Olive Oil on Acute Radiation Proctitis in Rats
}

\author{
Fatma Ayça Gültekin'1, Bekir Hakan Bakkal², Demet Sümer¹, Füruzan Köktürk³ ${ }^{3}$ Sibel Bektaş ${ }^{4}$ \\ ${ }^{1}$ Department of General Surgery, Bülent Ecevit University Faculty of Medicine, Zonguldak, Turkey \\ ${ }^{2}$ Department of Radiation Oncology, Bülent Ecevit University Faculty of Medicine, Zonguldak, Turkey \\ ${ }^{3}$ Department of Biostatistics, Bülent Ecevit University Faculty of Medicine, Zonguldak, Turkey \\ ${ }^{4}$ Department of Pathology, Bülent Ecevit University Faculty of Medicine, Zonguldak, Turkey
}

\begin{abstract}
Background: Acute radiation proctitis is a common complication of pelvic radiation and management of acute radiation proctitis is under evaluation. The beneficial effects of ozonated olive oil (OzOO) have already been shown in the treatment of chronic wounds. Thus, this study was designed to evaluate the therapeutic effects of topical $\mathrm{OzOO}$ on acute radiation proctitis.
\end{abstract}

Aims: To evaluate the therapeutic effects of topical OzOO on acute radiation proctitis.

Study Design: Animal experimentation.

Methods: Rats were divided into three groups: control; irradiation+saline (1 mL); and irradiation $+\mathrm{OzOO}(1 \mathrm{~mL})$. A single fraction of $17.5 \mathrm{~Gy}$ was delivered to each rat. The $\mathrm{OzOO}$ was administered rectally each day after irradiation. Each rat was observed daily for signs of proctitis. Irradiated rats were euthanised on days 5 and 10. The mucosal changes were evaluated macroscopically and pathologically.

Results: According to the clinical findings, five rats in the irradiation+saline group showed Grade 4 symptoms on the $10^{\text {th }}$ day. Macroscopic finding scores on the $10^{\text {th }}$ day in the irradiation+saline and irradiation+OzOO groups were statistically significantly different. On pathological examination, radiationinduced mucosal damage was the most prominent 10 days after irradiation in saline-treated rats. On the $10^{\text {th }}$ day, the irradiation+OzOO group showed mild inflammation and slight crypt change, which corresponded to Grade 1 pathological findings.

Conclusion: $\mathrm{OzOO}$ attenuates macroscopic and pathological findings of acute radiation proctitis in rats.

Key Words: Ozonated olive oil, radiation proctitis

Received: 20.05 .2013

Accepted: 22.07.2013

\section{Introduction}

Radiotherapy has paramount importance in the management of pelvic organ malignancies. However, pelvic location of the rectum and its anatomic relationship with other organs increase the risk of secondary radiation injury with resulting proctitis. Radiation injury may occur in an acute or chronic form. Acute radiation proctitis (ARP) is observed in $50-75 \%$ of patients, either during radiotherapy or up to 6 weeks after completion of radiotherapy, and symptoms of radiation injury decrease in 2-6 months. Symptoms of ARP are diarrhoea, intermittent bleeding, nausea, abdominal pain, mucous discharge, constipation, and various urinary symptoms (1). Inflammation, edema, epithelial degeneration, ulceration, crypt disintegration, mucosal edema, absent mitosis, and crypt abscesses are the histopathological changes found in $\operatorname{ARP}(2,3)$.

There have been numerous therapies with the aim to prevent or reduce the symptoms of radiation proctitis including medical therapy, such as corticosteroids $(4)$, sucralphate $(5,6)$, metronidazole (7), and formalin (8,9), endoscopic treatment, such as various lasers, including argon plasma coagulation (10), yttrium-aluminium-garnet laser (11), and treatment with hyperbaric oxygen $(12,13)$. However, suggested therapies of radiation proctitis have not proven to be effective, and their beneficial effects are limited. Therefore, the search for a more effective therapy continues.

Ozone $\left(\mathrm{O}_{3}\right)$ is well known as one of the best bactericidal, antiviral, and antifungal agents and is profitably and practically employed as Ozonated olive oil (OzOO) with well-defined peroxide contents. OzOO has been reported to be used topically for the treatment of war wounds, anaerobic infections, herpetic infections (HHV I and II), trophic ulcers and burns, cellulitis, abscesses, anal fissures, decubitus ulcers, fistulae, fungal diseases, furunculosis, gingivitis, and vulvovaginitis (14). It has been hypothesised that the mechanism of action of ozonated oil on wound healing may be connected in part to its antimicrobial effect but also to its ability to promote the generation of growth factors, activate local antioxidant mechanisms, and promote tissue repair (15). Therefore, the topical application of $\mathrm{OzOO}$ may produce beneficial effects in the management of ARP. In this study, we aimed to assess the efficacy of topical $\mathrm{OzOO}$ in the management of ARP.

\section{Material and Methods}

The experimental protocols were conducted with the approval of the Animal Research Committee at Bülent Ecevit Uni- 
versity, Zonguldak. All animals were maintained in accordance with the recommendations of the National Institutes of Health Guidelines for the Care and Use of Laboratory Animals.

\section{Animals}

Thirty-five female Wistar albino rats weighing 200-230 g at the age of 6 weeks were obtained from the Institute for Experimental Medicine, Bülent Ecevit University. All animals were acclimatised for 7 days prior to the experiments in the laboratory of the mentioned institute. Rats were housed in cages and were allowed free access to standard rat chow and water before and after the experiments. The animal rooms were windowless, with temperature $\left(22 \pm 2^{\circ} \mathrm{C}\right)$ and lighting controls. The animals were fasted overnight before the experiments but were given free access to water.

Rats were randomly divided into three groups: 14 animals in the irradiation (IR)+saline group; 14 animals in the IR+OzOO group; and seven animals in the control group. Both the saline and $\mathrm{OzOO}$ groups were irradiated in the pelvic area with 17.5 $\mathrm{Gy}$ as a single dose. For the $\mathrm{IR}+\mathrm{OzOO}$ group, $1 \mathrm{~mL} \mathrm{OzOO}$ was administered intrarectally twice a day from the day of IR until the day of euthanasia. For rats in the IR+saline group, the same protocol was performed with saline. The rats in the control group received no saline or $\mathrm{OzOO}$ and underwent sham IR.

\section{Pelvic irradiation}

Simulation of the IR was performed by computed tomography simulation. Each rat was anaesthetised using $5 \mathrm{mg} / \mathrm{kg}$ xylazine (Rompun, Bayer Türk, İstanbul, Turkey) and $30 \mathrm{mg} /$ kg ketamine hydrochloride (Ketalar, Pfizer, İstanbul, Turkey) delivered intramuscularly prior to IR. Then, three to four rats at a time were restrained and taped by the tail and legs on an acryl plate in a supine position. The rats were covered for a $3 \mathrm{~cm} \times 4 \mathrm{~cm}$ area of the lower pelvis containing a 2-cm length of the rectum in the middle of the field. IR was delivered with $6 \mathrm{MV}$ linear accelerator with the SAD technique. The irradiated area was verified by portal imaging. A bolus material was placed on the irradiated area. A dose of $17.5 \mathrm{~Gy}$ in a single fraction was delivered to each rat. A dose similar to this one has been shown to be optimal for clinically relevant proctitis using the same rat radiation model (16).

\section{Treatment with ozonated olive oil}

$\mathrm{OzOO}$ was generated by an ozone generator, which allowed control of the gas flow rate and ozone concentration in real time using a built-in ultraviolet (UV) spectrometer and was kept in a dark bottle at $4^{\circ} \mathrm{C}$ until used, within $24 \mathrm{~h}$. OzOO was produced at a concentration of approximately $14 \mu \mathrm{g}$ of ozone/mL of olive oil. The $\mathrm{OzOO}$, which was prepared in a 1 $\mathrm{mL}$ volume at body temperature, was given twice a day beginning on the first day after IR until the euthanasia day. The $\mathrm{OzOO}$ was applied with a soft feeding tube and then the anus was temporarily closed with a digital compress for 5 minutes.

\section{Evaluation of rectal damage}

Each rat was observed daily for signs of proctitis, such as diarrhoea and rectal bleeding, after IR. The clinical findings were scored as follows: 0 , no symptoms; 2, diarrhoea; and 4, gross bleeding. Seven rats were euthanised on each of the $5^{\text {th }}$ and $10^{\text {th }}$ days after IR for macroscopic and histological evaluation. Euthanasia was performed by cardiac exsanguination under a surgical plane of $100 \mathrm{mg} / \mathrm{kg}$ ketamine hydrochloride and $20 \mathrm{mg} / \mathrm{kg}$ xylazine anaesthesia. A midline laparotomy incision was made. The small bowel was moved aside to reveal the distal large bowel. The pelvic symphysis was cut and elevated to facilitate access to the distal rectum and anus. The $2 \mathrm{~cm}$ of distal rectum adjacent to the anal region was excised. The rectums were macroscopically evaluated and scored as follows (17): $0=$ normal mucosa; $1=e d e m a$, mild hyperaemia, or decreased vascularity; 2=diffuse hyperaemia, multiple punctuated areas of haemorrhage, or confluent areas of haemorrhage; $3=$ presence of erosions or frank haemorrhage; and 4=ulcers. For histological evaluation, a portion of the specimen was excised, fixed in $10 \%$ buffered formalin solution, embedded in paraffin, and cut into $5-\mu \mathrm{m}$ sections. The sections were stained with haematoxylin-eosin (HE) and examined under a light microscope by a blinded pathologist for histopathological changes. Each specimen was graded as follows (16): Grade 0, normal or minor alterations that cannot be correlated to radiation with certainty; Grade 1, slight radiation damage (mild inflammation and/or slight crypt change); Grade 2, mild damage (more significant inflammation and/or slight crypt change); Grade 3, moderate damage (must have prominent loss of epithelium and/or variable degree of inflammation); and Grade 4, severe damage (ulcer, necrosis).

\section{Statistical analysis}

Statistical analyses were performed with SPSS 18.0 software (SPSS Inc., Chicago, IL, USA). Kruskal-Wallis test was used to determine the differences between groups. Bonferroni-adjusted Mann-Whitney $U$ test was used for post-hoc test after the Kruskal-Wallis test ( $p$ values $<0.005$ were considered statistically significant).

\section{Results}

No mortality was observed in the groups. Differences in the mean body weight among the groups were found to be statistically significant $(p<0.001)$. The mean body weight on the $10^{\text {th }}$ day after IR was found to be significantly lower than that in the control group $(223.6 \pm 3.5 \mathrm{~g}) ; 204 \pm 3.1 \mathrm{~g}$ and $214.9 \pm 4.3 \mathrm{~g}$, control, IR+saline, and IR+OzOO groups, respectively $(p=0.001)$. However, the mean body weight on the $5^{\text {th }}$ day after IR was $215.4 \pm 4.9 \mathrm{~g}$ and $216 \pm 3.2 \mathrm{~g}$ in the $\mathrm{IR}+$ saline and IR+OzOO groups, respectively, with no significant difference.

The results of the clinical findings are listed in Table 1. Only two rats from the $\mathrm{IR}+\mathrm{OzOO}$ group were apparently healthy on the $5^{\text {th }}$ day, and their clinical finding scores were Grade 0 . Grade 2 symptoms were noted in six rats on the $5^{\text {th }}$ day in the IR+saline group, five rats on the $5^{\text {th }}$ day in the $\mathrm{IR}+\mathrm{OzOO}$ group, and five rats on the $10^{\text {th }}$ day in the $\mathrm{IR}+\mathrm{OzOO}$ group. On the $10^{\text {th }}$ day, the IR+saline group had a greater frequency of Grade 4 than did the other groups. Although on the $10^{\text {th }}$ day the IR+saline group had a higher clinical score than the 
IR+saline group on the $5^{\text {th }}$ day, the difference was not statistically significant (Table 2 ).

The scores of gross mucosal change are listed in Table 3. Macroscopic changes were maximal in the IR+saline group on the $10^{\text {th }}$ day. The numbers of rats showing Grade 1 and Grade 2 macroscopic findings were similar on the $5^{\text {th }}$ day in the IR+saline and IR+OzOO groups. Treatment with $\mathrm{OzOO}$ for 10 days following IR attenuated macroscopic findings in the $\mathrm{IR}+\mathrm{OzOO}$ group compared with the IR+saline group, 3.71 $( \pm 0.48)$ and $2.57( \pm 0.78)$, respectively. However, the difference between groups did not reach statistical significance (Table 2).

The most significant histopathological changes were observed in the IR+saline group on the $10^{\text {th }}$ day after IR (Table 4). Severe changes were characterised by the loss of epithe-

Table 1. Clinical findings

\begin{tabular}{|c|c|c|c|c|c|}
\hline \multirow[b]{2}{*}{ Characteristic } & \multirow[b]{2}{*}{$\begin{array}{c}\text { Control Group } \\
(n=7)\end{array}$} & \multicolumn{2}{|c|}{$5^{\text {th }}$ day } & \multicolumn{2}{|c|}{$10^{\text {th }}$ day } \\
\hline & & $\begin{array}{c}\text { IR+Saline } \\
\text { Group }(n=7)\end{array}$ & $\begin{array}{c}\text { IR+OzOO } \\
\text { Group }(n=7)\end{array}$ & $\begin{array}{c}\text { IR+Saline } \\
\text { Group }(n=7)\end{array}$ & $\begin{array}{c}\text { IR+OzOO } \\
\text { Group }(n=7)\end{array}$ \\
\hline Grade 0 & 7 & - & 2 & - & - \\
\hline Grade 2 & - & 6 & 5 & 2 & 5 \\
\hline Grade 4 & - & 1 & - & 5 & 2 \\
\hline
\end{tabular}

Table 2. Macroscopic findings

\begin{tabular}{|c|c|c|c|c|c|}
\hline \multirow[b]{2}{*}{ Characteristic } & \multirow[b]{2}{*}{$\begin{array}{l}\text { Control Group } \\
\qquad(n=7)\end{array}$} & \multicolumn{2}{|c|}{$5^{\text {th }}$ day } & \multicolumn{2}{|c|}{$10^{\text {th }}$ day } \\
\hline & & $\begin{array}{c}\text { IR+Saline } \\
\text { Group }(n=7)\end{array}$ & $\begin{array}{c}\text { IR+OzOO } \\
\text { Group }(n=7)\end{array}$ & $\begin{array}{c}\text { IR+Saline } \\
\text { Group }(n=7)\end{array}$ & $\begin{array}{c}\text { IR+OzOO } \\
\text { Group }(n=7)\end{array}$ \\
\hline Grade 0 & 7 & - & 3 & - & - \\
\hline Grade 1 & & 2 & 2 & - & 4 \\
\hline Grade 2 & - & 3 & 2 & 2 & 2 \\
\hline Grade 3 & & 2 & - & 5 & 1 \\
\hline Grade 4 & - & - & - & - & - \\
\hline
\end{tabular}

Table 3. Pathological findings

\begin{tabular}{|c|c|c|c|c|c|}
\hline \multirow[b]{2}{*}{ Characteristic } & \multirow[b]{2}{*}{$\begin{array}{c}\text { Control Group } \\
\qquad(n=7)\end{array}$} & \multicolumn{2}{|c|}{$5^{\text {th }}$ day } & \multicolumn{2}{|c|}{$10^{\text {th }}$ day } \\
\hline & & $\begin{array}{c}\text { IR+Saline } \\
\text { Group }(n=7)\end{array}$ & $\begin{array}{c}\text { IR+OzOO } \\
\text { Group }(n=7)\end{array}$ & $\begin{array}{c}\text { IR+Saline } \\
\text { Group }(n=7)\end{array}$ & $\begin{array}{c}\text { IR+OzOO } \\
\text { Group }(n=7)\end{array}$ \\
\hline Grade 0 & 7 & - & - & - & - \\
\hline Grade 1 & - & - & 5 & - & 4 \\
\hline Grade 2 & - & 5 & 2 & - & 2 \\
\hline Grade 3 & - & 2 & - & 5 & 1 \\
\hline Grade 4 & - & - & - & 2 & - \\
\hline
\end{tabular}

Table 4. Comparison of the clinical, macroscopic, and pathological finding scores

\begin{tabular}{|lccc|}
\hline Day and Rat Group & Clinical finding score & Macroscopic finding score & Pathological finding score \\
\hline $5^{\text {th }}$ day IR+Saline & $2.14(2-3)$ & $3(2-4)$ & $2.29(2-3)$ \\
$5^{\text {th }}$ day IR+OzOO & $1.71(1-2)$ & $2(1-3)$ & $1.29(1-2)$ \\
$10^{\text {th }}$ day IR+Saline & $2.71(2-3)$ & $3.71(3-4)$ & $3.29(3-4)$ \\
$10^{\text {th }}$ day IR+OzOO & $2.29(2-3)$ & $2.57(2-4)$ & $1.86(1-3)^{*}$ \\
\hline * $\mathrm{p}=0.002$ versus the IR+saline group on the 10 & & \\
IR: irradiation; OzOO: ozonated olive oil & & \\
\hline
\end{tabular}


lium through the muscularis mucosa and mucosal ulceration (Figure 1). Comparing the histological changes in the $5^{\text {th }}$ and $10^{\text {th }}$ day specimens, the most prominent changes in the $5^{\text {th }}$ day specimens were moderate inflammation and slight crypt change (Figure 1). Although not found to be statistically significant, the IR+saline group had milder histopathological changes on the $5^{\text {th }}$ day than the IR+saline group did on the $10^{\text {th }}$ day. OzOO attenuated pathological findings of ARP. Five rats in the $\mathrm{IR}+\mathrm{OzOO}$ group on the $5^{\text {th }}$ day and four rats in the $\mathrm{IR}+\mathrm{OzOO}$ group on the $10^{\text {th }}$ day showed Grade 1 histopathological changes (Figure 1). Pathological finding score was decreased on the $5^{\text {th }}$ day in the IR+OzOO group $(2.29 \pm 0.48)$ compared with that on the $5^{\text {th }}$ day in the IR+saline group (3.29 \pm 0.48 , Table 2). However, no significant difference was found regarding the pathological finding score between the groups on the $5^{\text {th }}$ day. OzOO treatment for 10 days after IR significantly reduced inflammation and crypt changes, and the difference between the $\mathrm{IR}+$ saline and $\mathrm{IR}+\mathrm{OzOO}$ groups on the $10^{\text {th }}$ day was statistically significant $(p=0.002)$ (Table 2$)$.

\section{Discussion}

ARP is characterised by an inflammatory process involving only the superficial mucosa (18) that develops immediately after the initiation of therapy or up to 3 months after the onset of therapy (19). Symptoms including diarrhoea, nausea, cramps, tenesmus, urgency, mucus discharge, and minor bleeding may occur in up to $20 \%$ of patients, leading to an interruption in treatment (20). Much research has been con- ducted to define best therapy for prevention or reduction of symptoms of ARP.

Radiation therapy results in oxidative stress and it has been demonstrated that free oxygen radicals have a crucial role in radiation-induced normal tissue toxicity and in inflammation. The increase in antioxidant enzyme levels may prevent damage of IR to normal tissues and reduce the inflammation (6). Ozone therapy has beneficial effects in various diseases, such as caustic oesophageal burn, diabetic foot, and radiationinduced cystitis (21-23). It can be applied by topical, rectal, peritoneal (animal studies), or oral (ozonised water or oil) routes. The term 'ozone oxidative preconditioning' refers to the repeated application of ozone in order to increase antioxidant enzymes and keep the organism alert, as in vaccination. Ozone oxidative preconditioning provides protection against the cellular damage caused by free radicals (24). In our previous study, we also investigated the effects of ozone oxidative preconditioning in the prevention of acute radiation toxicity in rat liver and intestine. Ozone was found to be effective for the prevention of radiation-induced ileal injury (25). However, data on the use of ozone or ozonated oils in radiation proctitis are limited. Recently, Clavo et al. (26) reported the beneficial effects of ozone therapy on refractory haemorrhagic radiation proctitis. In the study, 17 patients received an ozone gas mixture via rectal insufflations and topical application of ozonised oil, and were followed up for a median of 40 months (3-56 months). Clavo et al. (26) concluded that ozone treatment improved the clinical symptoms of haemorrhagic radiation proctitis. However, this is the only study published in the English-

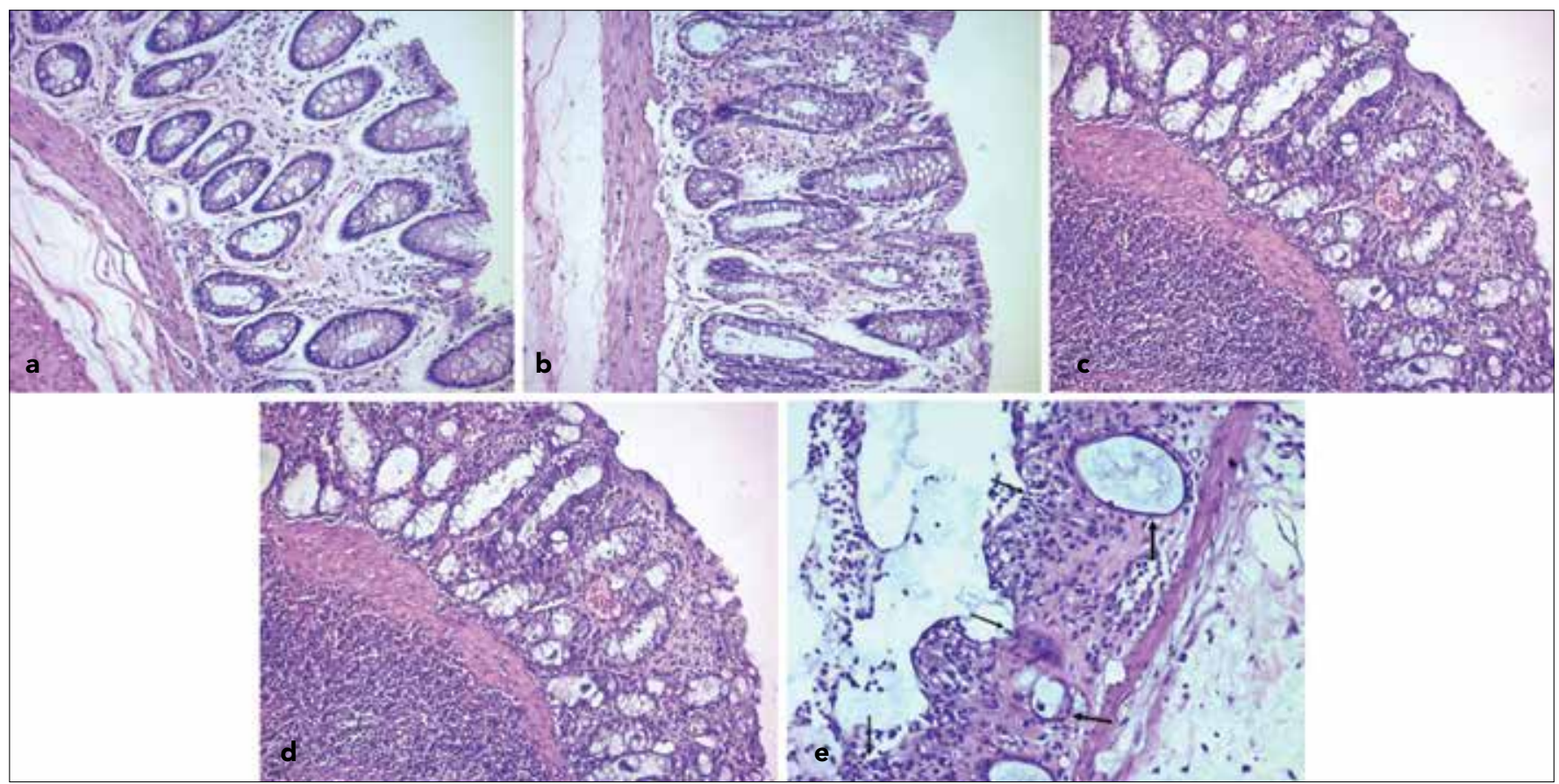

Figure 1. a-e. Normal rectal mucosa (Grade 0) in the control group (H\&E, x200) (a). Grade 1 histological change: mild inflammation and slight crypt change in ozone-treated groups on the $5^{\text {th }}$ day (H\&E, x200) (b). Grade 2 histological change: moderate inflammation and slight crypt change in ozone-treated groups on the 10th day (H\&E, x200) (c). Grade 3 histological change: prominent loss of epithelium (arrow) and severe inflammation in radiation-treated groups on the $5^{\text {th }}$ day (H\&E, x200) (d). Grade 4 histological change: severe crypt damage (thick arrows), inflammation, and ulceration (thin arrows) in radiation-treated groups on the $10^{\text {th }}$ day (H\&E, x200) (e) 
language literature, and to date, no studies have reported the effects of OzOO on histopathological findings of ARP in animals or in humans.

In the present study, the sequential changes following IR were observed in rats. In the clinical findings, results that were greater than Grade 2 findings were found in saline-treated groups on the $10^{\text {th }}$ day following $I R$, whereas only one rat showed Grade 4 findings on the $5^{\text {th }}$ day in the IR+saline group. Although fewer Grade 4 clinical findings, which included diarrhoea and melaena, were observed on the $10^{\text {th }}$ day in the $\mathrm{IR}+\mathrm{OzOO}$ group, no significant differences were found between the groups on the $10^{\text {th }}$ day in terms of clinical findings.

Grossly, ARP is an inflammatory process of the rectal mucosa that appears oedematous, beefy red, and may have ulceration or sloughing. The present study evaluated mucosal changes on the $5^{\text {th }}$ and $10^{\text {th }}$ days after IR. Apparent mucosal changes were observed on the $10^{\text {th }}$ day in the IR+saline group. The macroscopic findings were consistent with those from previous reports. Kang et al. (16) reported that erosion of the surface epithelium, which started on the $6^{\text {th }}$ day after $\mathrm{IR}$, progressed to multifocal ulceration with severe inflammation until the $10^{\text {th }}$ day after IR. Macroscopic finding score on the $10^{\text {th }}$ day after IR was 3.71 , which meant that most specimens revealed Grade 3 findings, and intrarectal application of $\mathrm{OzOO}$ for 10 days improved macroscopic mucosal changes of ARP, but the difference was not significant.

Mucosal damage in the rectum was evaluated pathologically, and the pathological findings were consistent with those from previous reports $(3,16,17)$. The pathological differences on the $10^{\text {th }}$ day in the IR+saline group were more obvious, and mucosal ulceration and crypt damage were the predominant characteristics of acute radiation toxicity. OzOO-treated groups had statistically significantly lower scores.

In the present study, the rectum was examined clinically, macroscopically, and pathologically, and the rats that received $\mathrm{OzOO}$ tended to show milder rectal damage than the other groups for all criteria of the study. However, the differences did not reach statistical significance in terms of clinical and macroscopic finding scores. On the $10^{\text {th }}$ day, the IR+saline group had a significantly higher pathological finding score than the $\mathrm{IR}+\mathrm{OzOO}$ group. Moreover, 10-day OzOO treatment appeared to be more effective than 5-day $\mathrm{OzOO}$ treatment after IR in the study. Thus, OzOO was confirmed to have beneficial effects on ARP. Ozone was chosen for its demonstrated benefits in radiation-induced cystitis (23), refractory haemorrhagic radiation proctitis (26), and ileal injury (25). Calvo et al. (23) reported that ozonated bi-distilled water could be administered intravesicularly to prevent haematuria caused by radiation-induced cystitis. More recently, the authors also reported their experience with ozone therapy in the treatment of refractory haemorrhagic radiation proctitis. Oxygen radicals in radiationinduced gastrointestinal disorders have been demonstrated, and in our previous study, intraperitoneally administered ozone was shown to protect against radiation-induced mucosal injury of the small bowel (25). The radioprotection observed with ozone is attributed to an increase in the endogenous antioxidative defence enzymes and the inhibition of lipid peroxidation.
Some authors have investigated various antioxidant agents in the prevention of acute radiation toxicity. In a study by Doi et al. (27), the use of intrarectal polaprezinc significantly attenuated ARP in rats. Similarly, Yoon et al. (28) found that oral high-dose triphala treatment improved radiation-induced acute intestinal mucosal damage in rats. Moreover, it has been generally accepted that IR damages endothelial cells in the microvessels and causes hypoxaemia (29). It is possible that the effect of ozone reduces the presence of phagocytic cells, thereby reducing the oxidative burst, increasing the oxygen tension, and ameliorating the radiation-induced mucosal damage. In the experiments on full-thickness dermal wound treated with ozonated oils $(30,31)$, a rise in wound healing rate was reported. Those reports suggested that increased oxygen tension at the wound site increased the formation of granulation tissue, accelerated wound closure, and ameliorated impaired dermal wound healing. Although those reports are not related to radiation protection or mucosa, we can infer that a similar mechanism might be involved from the standpoint of the recovery or re-epithelialisation of damaged tissue. Further studies are required to clarify the mechanism underlying the beneficial effect of OzOO on ARP.

In the literature, the effects of $\mathrm{OzOO}$ therapy on radiation proctitis are based on a limited number of scientific studies, often involving small numbers of patients with variable periods of follow-up, and considering only clinical and macroscopic findings. Although we used an animal model of radiation proctitis, we were able to evaluate the effects of $\mathrm{OzOO}$ in terms of clinical, macroscopic, and histopathological findings. We conclude that in the treatment of ARP, OzOO given rectally for 10 days reduced rectal mucosal damage, as shown by macroscopic and histopathological findings in rats. However, more research is needed to confirm the beneficial effects of $\mathrm{OzOO}$ in radiation-induced proctitis. In addition, clinical trials should be conducted to determine whether $\mathrm{OzOO}$ could reduce the severity and frequency of early complications of IR.

Ethics Committee Approval: Ethical approval was received from the Animal Research Committee of Bülent Ecevit University in May 5th, 2013 (2012-23-30/05).

\section{Informed Consent: N/A}

Peer-review: Externally peer-reviewed.

Author contributions: Concept - F.A.G.; Design - F.A.G., B.H.K.; Supervision - F.A.G.; Resource - F.A.G., B.H.K.; Materials - F.A.G., B.H.K.; Data Collection\&/or Processing - F.A.G., B.H.K., D.S., S.B.; Analysis\&/or Interpretation - F.K.; Literature Search - F.A.G.; Writing - F.A.G.; Critical Reviews - F.A.G.

Conflict of Interest: The authors declared no conflict of interest

Financial Disclosure: The authors declared that this study received no financial support.

\section{References}

1. Hauer-Jensen M, Wang J, Denham JW. Bowel injury: current and evolving management strategies. Semin Radiat Oncol 2003;13:357-71.

2. Hovdenak N, Fajardo LF, Hauer-Jensen M. Acute radiation proctitis:a sequential clinicopathologic study during pelvic radiotherapy. Int J Radiat Oncol Biol Phys 2000;48:1111-7. [CrossRef] 
3. Korkut C, Asoglu O, Aksoy M, Kapran Y, Bilge H, Kiremit-Korkut $\mathrm{N}$, et al. Histopathological comparison of topical therapy modalities for acute radiation proctitis in an experimental rat model. World J Gastroenterol 2006;12:4879-83.

4. Sherman LF, Prem KA, Mensheha NM. Factitial proctitis: A restudy at the University of Minesota. Dis Colon Rectum 1971;14:281-5. [CrossRef]

5. Kneebone A, Mameghan H, Bolin T, Berry M, Turner S, Kearsley J, et al. Effect of oral sucralfate on late rectal injury associated with radiotherapy for prostate cancer: A double-blind, randomized trial. Int J Radiat Oncol Biol Phys 2004;60:1088-97. [CrossRef]

6. Kochhar R, Patel F, Dhar A, Sharma SC, Ayyagari S, Aggarwal R, et al. Radiation-induced proctosigmoiditis:Prospective, randomized, double-blind controlled trial of oral sulfasalazine plus rectal steroids versus rectal sucralfate. Dig Dis Sci 1991;36:103-7. [CrossRef]

7. Cavcic J, Turcic J, Martinac P, Jelincic Z, Zupancic B, PanijanPezerovic $\mathrm{R}$, et al. Metronidazole in the treatment of chronic radiation proctitis: Clinical trial. Croat Med J 2000;41:314-8.

8. Tsujinaka S, Baig MK, Gornev R, de la Garza C, Hwang JK, Sands $D$, et al. Formalin instillation for hemorrhagic radiation proctitis. Surg Innov 2005;12:123-8. [CrossRef]

9. Parikh S, Hughes C, Salvati EP, Eisenstat T, Oliver G, Chinn B, et al. Treatment of hemorrhagic radiation proctitis with 4 percent formalin. Dis Colon Rectum 2003;46:596-600. [CrossRef]

10. Karamanolis G, Triantafyllou K, Tsiamoulos Z, Polymeros D, Kalli $\mathrm{T}$, Misailidis N, et al. Argon plasma coagulation has a long-lasting therapeutic effect in patients with chronic radiation proctitis. Endoscopy 2009;41:529-31. [CrossRef]

11. Ventrucci M, Di Simone MP, Giulietti P, De Luca G. Efficacy and safety of $\mathrm{Nd}$ :YAG laser for the treatment of bleeding from radiation proctocolitis. Dig Liver Dis 2001;33:230-3. [CrossRef]

12. Nakabayashi M, Beard C, Kelly SM, Carr-Locke DL, Oh WK. Treatment of a radiation-induced rectal ulcer with hyperbaric oxygen therapy in a man with prostate cancer. Urol Oncol 2006;24:5038. [CrossRef]

13. Allen S, Kilian C, Phelps J, Whelan HT. The use of hyperbaric oxygen for treating delayed radiation injuries in gynecologic malignancies: a review of literature and report of radiation injury incidence. Support Care Cancer 2012;20:2467-72. [CrossRef]

14. Bocci V. Ozone: A New Medical Drug. Dordrecht: Springer, 2005;32-5, 102-3.

15. Oosting RS, Van Rees-Verhoef M, Verhoef J, Van Golde LM, Van Bree L. Effects of ozone on cellular ATP levels in rat and mouse alveolar macrophages. Toxicology 1991;70:195-202. [CrossRef]

16. Kan S, Chun M, Jin YM, Cho MS, Oh YT, Ahn BO, et al. A rat model for radiation-induced proctitis. J Korean Med Sci 2000;15:682-9.

17. Northway MG, Scobey MW, Geisinger KR. Radiation proctitis in the rat. Sequential changes and effects of anti-inflammatory agents. Cancer 1988;62:1962-9. [CrossRef]
18. Denton AS, Forbes A, Andreyev J, Maher EJ. Non-surgical interventions for late radiation proctitis in patients who have received radical radiotherapy to the pelvis. Cochrane Database Syst Rev 2002; CD003455.

19. Denton AS, Andreyev HJ, Forbes A, Maher EJ. Systematic review for non-surgical interventions for the management of late radiation proctitis. Br J Cancer 2002;8:134-43. [CrossRef]

20. Cotti G, Seid V, Araujo S, Souza AH Jr, Kiss Dr, Habr-Gama A. Conservative therapies for hemorrhagic radiation proctitis:a review. Rev Hosp Clin Fac Med Sao Paulo 2003;58:284-92. [CrossRef]

21. Guven A, Gundogdu G, Sadir S, Topal T, Erdogan E, Korkmaz $A$, et al. The efficacy of ozone therapy in experimental caustic esophageal burn. J Pediatr Surg 2008;43:1679-84. [CrossRef]

22. Martínez-Sánchez G, Al-Dalain SM, Menéndez S, Re L, Giuliani A, Candelario-Jalil $E$, et al. Therapeutic efficacy of ozone in patients with diabetic foot. Eur J Pharmacol 2005;523:151-61. [CrossRef]

23. Clavo B, Gutierrez D, Martin D, Suarez G, Hernandez MA, Robaina $F$. Intravesical ozone therapy for progressive radiation-induced hematuria. J Altern Complement Med 2005;11:539-41. [CrossRef]

24. Leon OS, Menendez S, Merino N, Castillo R, Sam S, Perez L, et al. Ozone oxidative preconditioning:a protection against cellular damage by free radicals. Mediators Inflamm 1998;7:289-94. [CrossRef]

25. Gultekin FA, Bakkal BH, Guven B, Tasdoven I, Bektas S, Can M, et al. Effects of ozone oxidative preconditioning on radiation-induced organ damage in rats. J Radiat Res 2013;54:36-44. [CrossRef]

26. Clavo B, Ceballos D, Gutierrez D, Rovira G, Suarez G, Lopez L, et al. Long-term control of refractory hemorrhagic radiation proctitis with ozone therapy. J Pain Symptom Manage 2013;46:106-12. [CrossRef]

27. Doi H, Kamikonya N, Takada Y, Fujiwara M, Tsuboi K, Inoue H, et al. Efficacy of polaprezinc for acute radiation proctitis in a rat model. Int J Radiat Oncol Biol Phys 2011;80:877-84. [CrossRef]

28. Yoon WS, Kim CY, Yang DS, Park YJ, Park W, Ahn YC, et al. Protective effect of triphala on radiation induced acute intestinal mucosal damage in Sprague Dawley rats. Indian J Exp Biol 2012;50:195-200.

29. Liu Y, Kudo K, Abe Y, Hu DL, Kijima H, Nakane A, et al. Inhibition of transforming growth factor-beta, hypoxia-inducible factor-1alpha and vascular endothelial growth factor reduced late rectal injury induced by irradiation. J Radiat Res 2009;50:233-9. [CrossRef]

30. Kim HS, Noh SU, Han YW, Kim KM, Kang H, Kim HO, et al. Therapeutic effects of topical application of ozone on acute cutaneous wound healing. J Korean Med Sci 2009;24:368-74. [CrossRef]

31. Valacchi G, Lim Y, Belmonte G, Miracco C, Zanardi I, Bocci V, et al. Ozonated sesame oil enhances cutaneous wound healing in SKH1 mice. Wound Repair Regen 2011;19:107-15. [CrossRef] 